\title{
A review of the most common patient-reported outcomes in COPD - revisiting current knowledge and estimating future challenges
}

This article was published in the following Dove Press journal:

International Journal of COPD

7 April 2015

Number of times this article has been viewed

\author{
Mario Cazzola' \\ Nicola Alexander Hanania ${ }^{2}$ \\ William $\mathrm{MacNe}^{3}$ \\ Katja Rüdell ${ }^{4}$ \\ Claire Hackford ${ }^{4}$ \\ Nihad Tamimi ${ }^{4}$ \\ 'University of Rome 'Tor Vergata', \\ Department of Medicine of Systems, \\ Unit of Respiratory Clinical \\ Pharmacology, Rome, Italy; ${ }^{2}$ Section \\ of Pulmonary, Critical Care and Sleep \\ Medicine, Baylor College of Medicine, \\ Houston, TX, USA; ${ }^{3}$ University \\ of Edinburgh/MRC Centre for \\ Inflammation Research, The Queen's \\ Medical Research Institute, Edinburgh, \\ United Kingdom; ${ }^{4}$ Patient Reported \\ Outcome Center of Excellence, \\ Global Market Access, Primary Care \\ Business Unit, Pfizer, Tadworth, United \\ Kingdom
}

Correspondence: Mario Cazzola University of Rome 'Tor Vergata', Department of Medicine of Systems, Unit of Respiratory Clinical Pharmacology, Via Montpellier I, Rome 00I33, Italy Tel +39062090 0631

Email mario.cazzola@uniroma2.it

\begin{abstract}
Patient-reported outcome (PRO) measures that quantify disease impact have become important measures of outcome in COPD research and treatment. The objective of this literature review was to comprehensively evaluate psychometric properties of available PRO instruments and the ability of each of them to characterize pharmaceutical treatment effects from published clinical trial evidence. Identified in this study were several PRO measures, both those that have been used extensively in COPD clinical trials (St George's Respiratory Questionnaire and Chronic Respiratory Questionnaire) and new instruments whose full value is still to be determined. This suggests a great need for more information about the patient experience of treatment benefit, but this also may pose challenges to researchers, clinicians, and other important stakeholders (eg, regulatory agencies, pharmaceutical companies) who develop new treatment entities and payers (including but not limited to health technology assessment agencies such as the National Institute for Health and Care Excellence and the Canadian Agency for Drugs and Technologies in Health). The purpose of this review is to enable researchers and clinicians to gain a broad overview of PRO measures in COPD by summarizing the value and purpose of these measures and by providing sufficient detail for interested audiences to determine which instrument may be the most suitable for evaluating a particular research purpose.
\end{abstract}

Keywords: COPD, patient reported outcome, health related quality of life, quality of life, psychometric properties

\section{Introduction}

COPD is a complex, multicomponent, chronic condition that is characterized by progressive airflow limitation that is not fully reversible. ${ }^{1}$ Progressive deterioration of lung function together with other comorbidities imposes various impacts on the patients' physical condition, functioning, and health related quality of life (HRQoL). ${ }^{1,2}$ Patients with COPD show progressive decline in lung function, and they show the exacerbations that the condition brings with it: breathlessness (dyspnea) on exertion; cough and sputum production; and reduced exercise capacity. ${ }^{2}$ Because measurement of forced expiratory volume in 1 second $\left(\mathrm{FEV}_{1}\right)$ is the most repeatable lung function parameter, it is usually the primary parameter used to assess patient outcome, to classify patients by severity, and to measure disease progression both in clinical trials and in clinical practice. ${ }^{1,2}$ Therefore, changes in $\mathrm{FEV}_{1}$ are often used to adapt treatment strategies and to test the effectiveness of various treatments in COPD patients. However, this strategy falls short, as it has been well documented that changes in FEV do not correlate well with changes in COPD symptoms and correlate only modestly with health status or other patient-reported outcome (PRO) measures.$^{3-6}$ In addition to 
pulmonary manifestations, patients with COPD may develop other systemic problems and comorbidities ${ }^{1,2}$ that contribute significantly to reduced exercise capacity and HRQoL, but none of these are reflected in changes in $\mathrm{FEV}_{1}{ }^{7}$ Therefore, recent treatment guidelines for COPD have recommended the inclusion of symptom assessments such as the COPD Assessment Test ${ }^{8}$ (CAT) and the modified Medical Research Council (m-MRC) $)^{9}$ dyspnea scale to fully assess patients. ${ }^{1}$ In clinical practice, it is important that spirometry be accompanied by other assessments that use relevant PRO measures to evaluate the response to treatment. ${ }^{10,11}$

\section{PROs}

The use of a PRO as a primary or a secondary endpoint in clinical trials has become more widespread in recent years, and guidance on the use of PROs in clinical trials has been recently published. ${ }^{12}$ Typically, PROs present the patient perspective of treatment benefit and can be used to assess and monitor disease progression, exacerbation of symptoms, or adverse effects of treatment. ${ }^{13-17}$ Key concepts in COPD that have significant impact on a patient's HRQoL include breathlessness/dyspnea, fatigue, cough and sputum production, physical functioning, social functioning, and exacerbations. ${ }^{2,18}$ In order to evaluate the effects of treatment that are relevant to patients with COPD, PRO instruments need to be fit for the purpose: they should be valid, reliable, and responsive to clinically meaningful treatment effects in COPD. This review provides an overview of the most commonly used PROs that are condition-specific to COPD. We evaluated the role of PROs in assessing treatment benefit, as well as their abilities to evaluate health status and well- being of patients. This study differs from a systematic review of PRO instruments published by Weldam et al in 2013, which evaluated the psychometric criteria of the instruments with each other and concluded that there is too little evidence to recommend generic HRQoL instruments for use in COPD care. ${ }^{19}$ In this article, we describe the characteristics of the most commonly used COPD instruments in more detail so that individuals who are looking to use PRO instruments in studies can get a reasonable insight into the benefits and characteristics of each instrument. Furthermore, instruments that were not available in 2012, such as the Exacerbations of Chronic Pulmonary Disease Tool (EXACT) and the Exacerbations of Chronic Pulmonary Disease Respiratory Symptoms (E-RS), are detailed in this study.

\section{Methods}

A literature search was conducted to retrieve articles describing tools for measuring COPD PROs (symptoms, health status, functioning, and HRQoL) and their development. References for this review were identified through searches in PubMed for articles published with the terms "chronic obstructive pulmonary disease", "COPD”, "patient reported outcomes", "health related quality of life", "health status questionnaires", “exacerbation measures", or "breathlessness measures". Relevant published articles found through searches in the author's personal files and in Google Scholar were also included. Articles resulting from these searches and relevant references and citations were also included in the review. No date was set for inclusion of articles; included were those publications that were in English and based on some information of psychometric validation to ensure the validity of the instrument development. Excluded were articles about generic HRQoL instruments such as the SF-36 and articles about functioning measures that were not specific to COPD or used in clinical trials of studies that compared treatment benefit.

\section{Results}

\section{Frequently used PRO measures in COPD}

High level psychometric information (including minimal important difference) about the commonly used PRO instruments is presented in Tables 1 and 2. The paper will further provide a short instrument-by-instrument description as a quick reference guide.

\section{Health status and HRQoL measures} St George's Respiratory Questionnaire (SGRQ) The SGRQ is a 50-item, self-administered measure that evaluates HRQoL in individuals with chronic airflow limitation. ${ }^{20-22}$ This tool has been developed with patient input and with the response to each of its items weighted by using patient derived-weights. This strategy of empirical determination of different item weights overcomes the methodological challenge of obtaining an overall measure of the symptomatic impact of the disease. The SGRQ has well documented content validity and has shown good reliability and validity. ${ }^{23,24}$ The SGRQ has been recommended as a suitable HRQoL instrument that can be used in drug development programs and clinical trials in a UK report to the department of health, European Medicines Agency, ${ }^{25}$ as well as mentioned as a suitable endpoint in the COPD draft guidance by the US Food and Drug Administration (FDA). ${ }^{14}$ The SGRQ has also been widely used in clinical trials, including many pivotal trials in COPD, because its discriminative and evaluative properties and predictive validity have been established and its responsiveness to pharmacological 


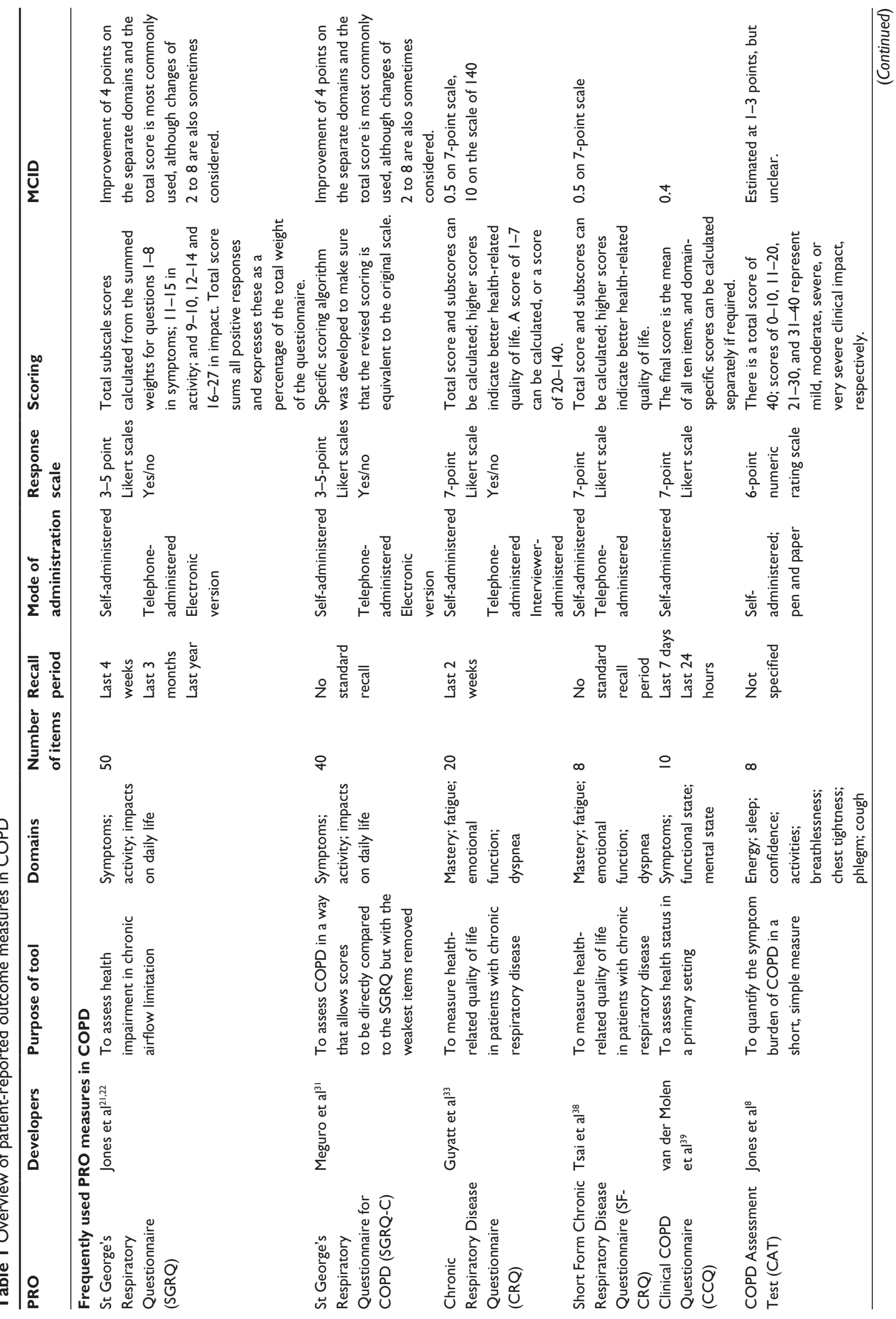




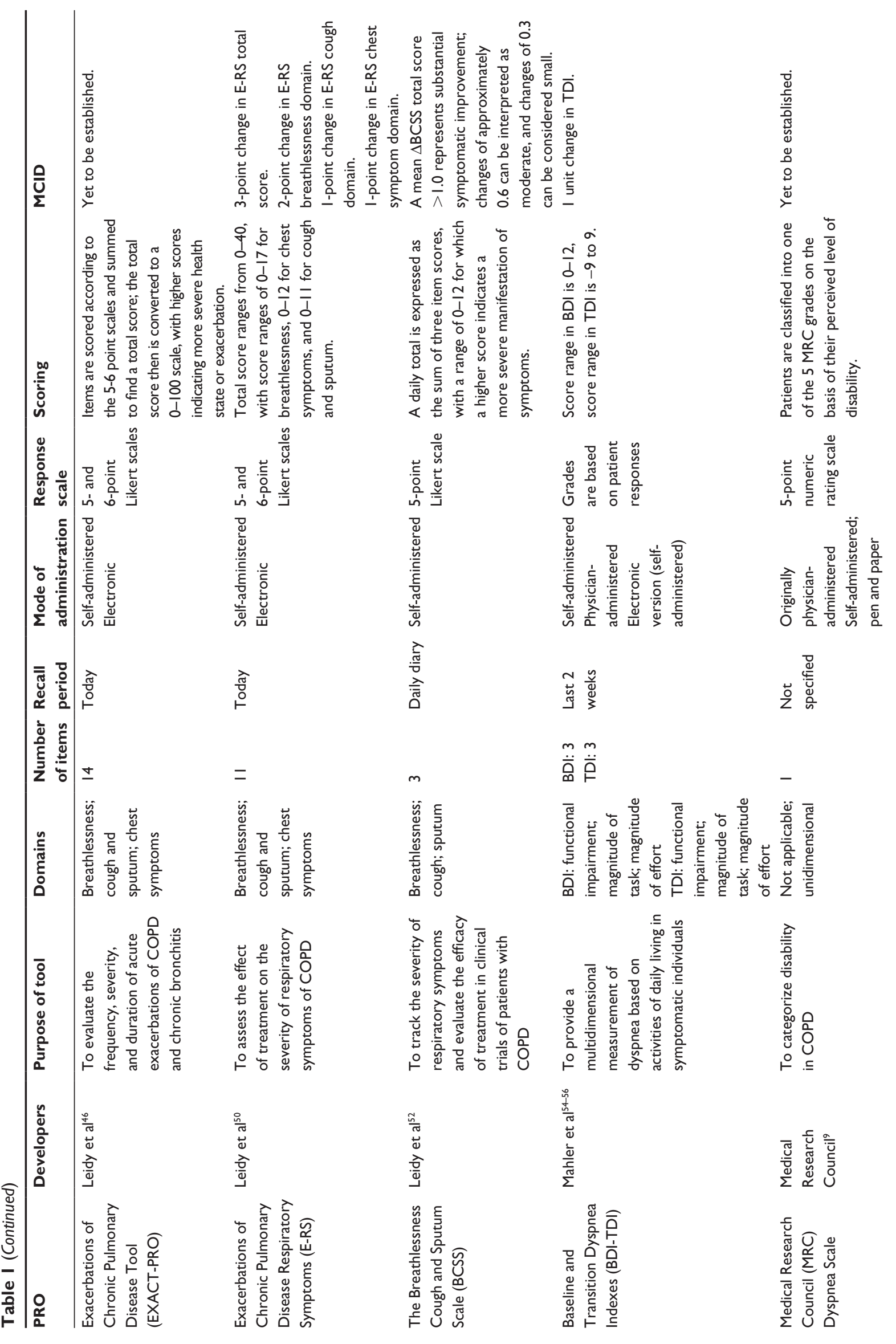




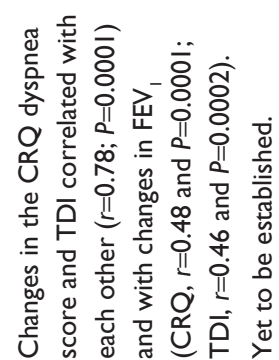

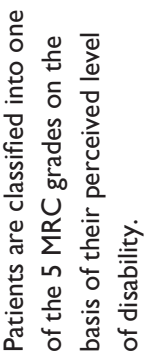

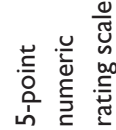

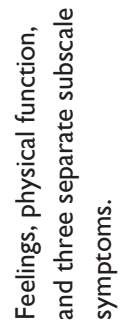

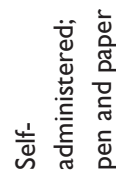

雚离离

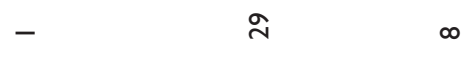

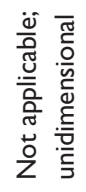

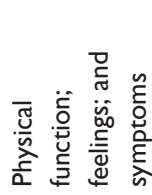

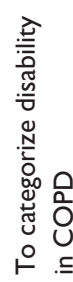

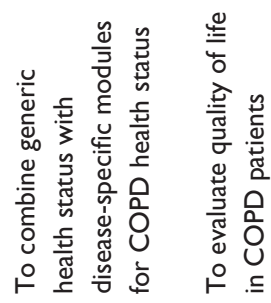

$\frac{\sqrt{0}}{\frac{\pi}{2}}$

$\stackrel{\square}{\circ}$
$\frac{0}{0}$
$\frac{0}{4}$

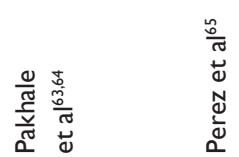

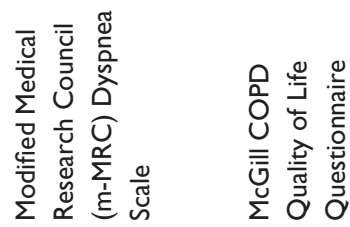

$\infty$ $\stackrel{\dot{m}}{\mathrm{~m}}$

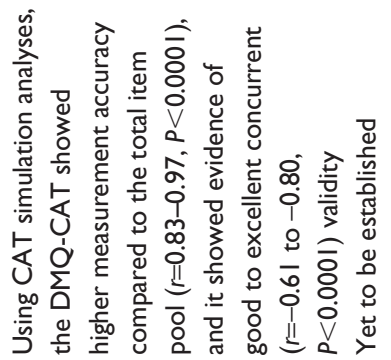

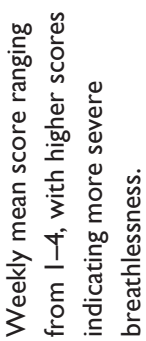

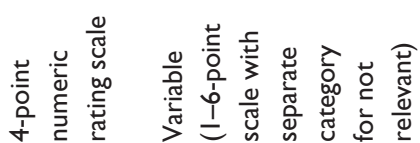

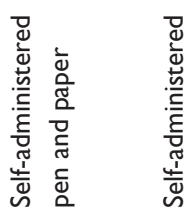

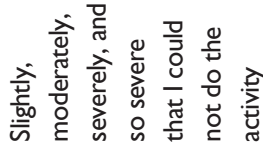

登

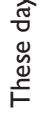

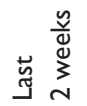

츰

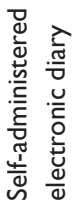

$\simeq \quad \overline{1}$

$\underline{m}$

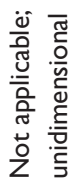

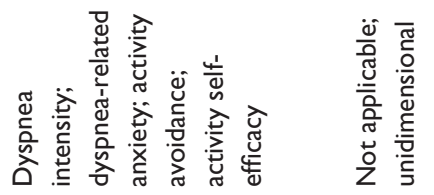

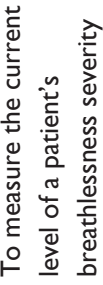

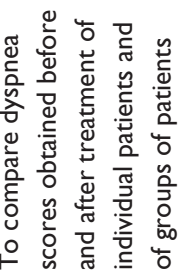

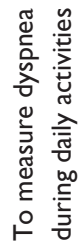

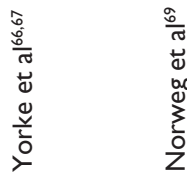

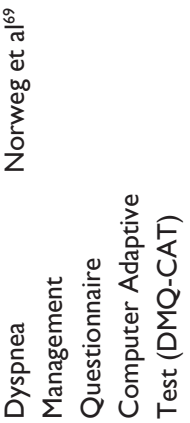

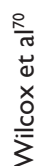

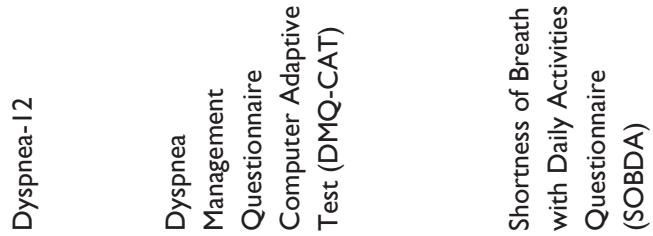



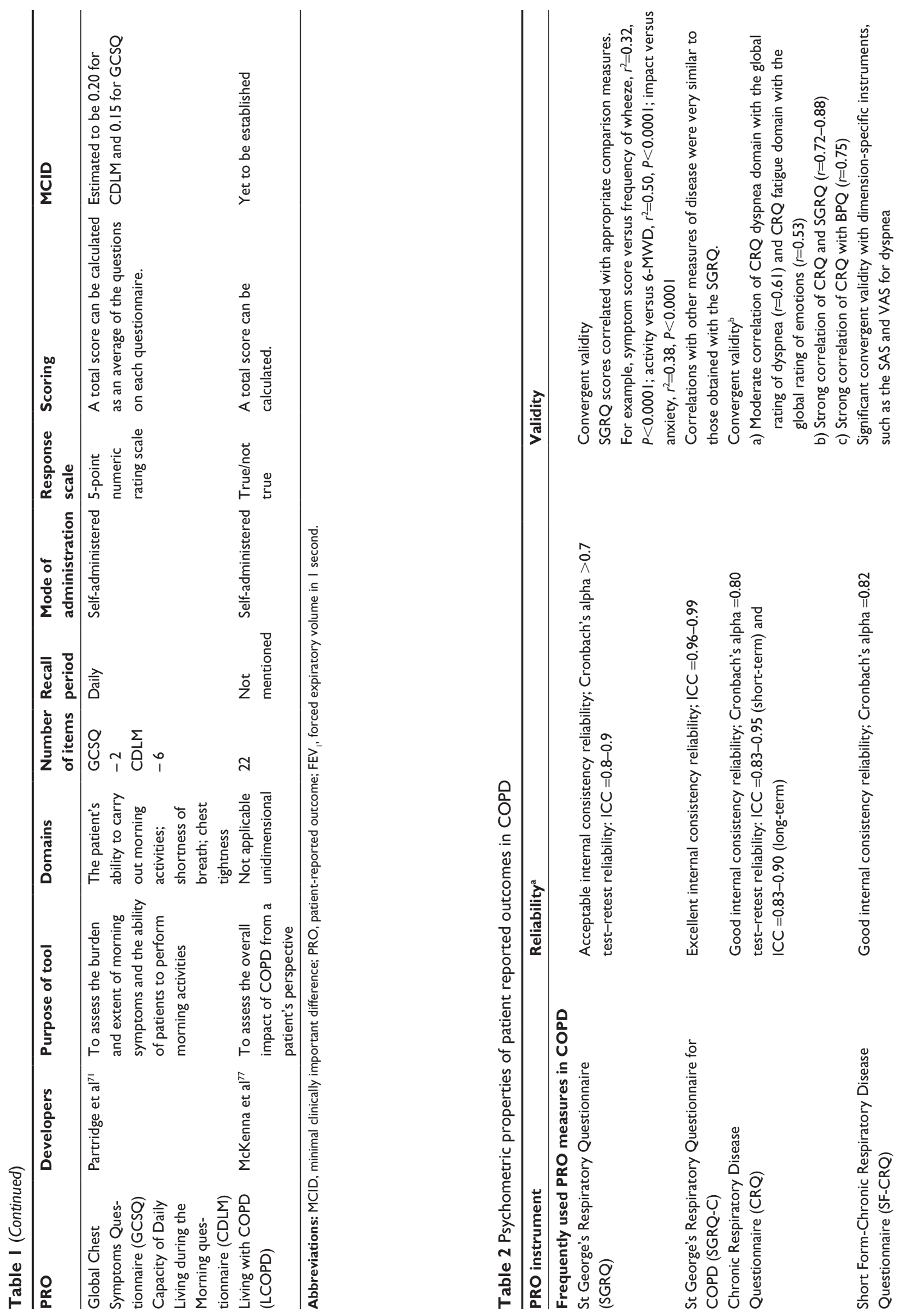


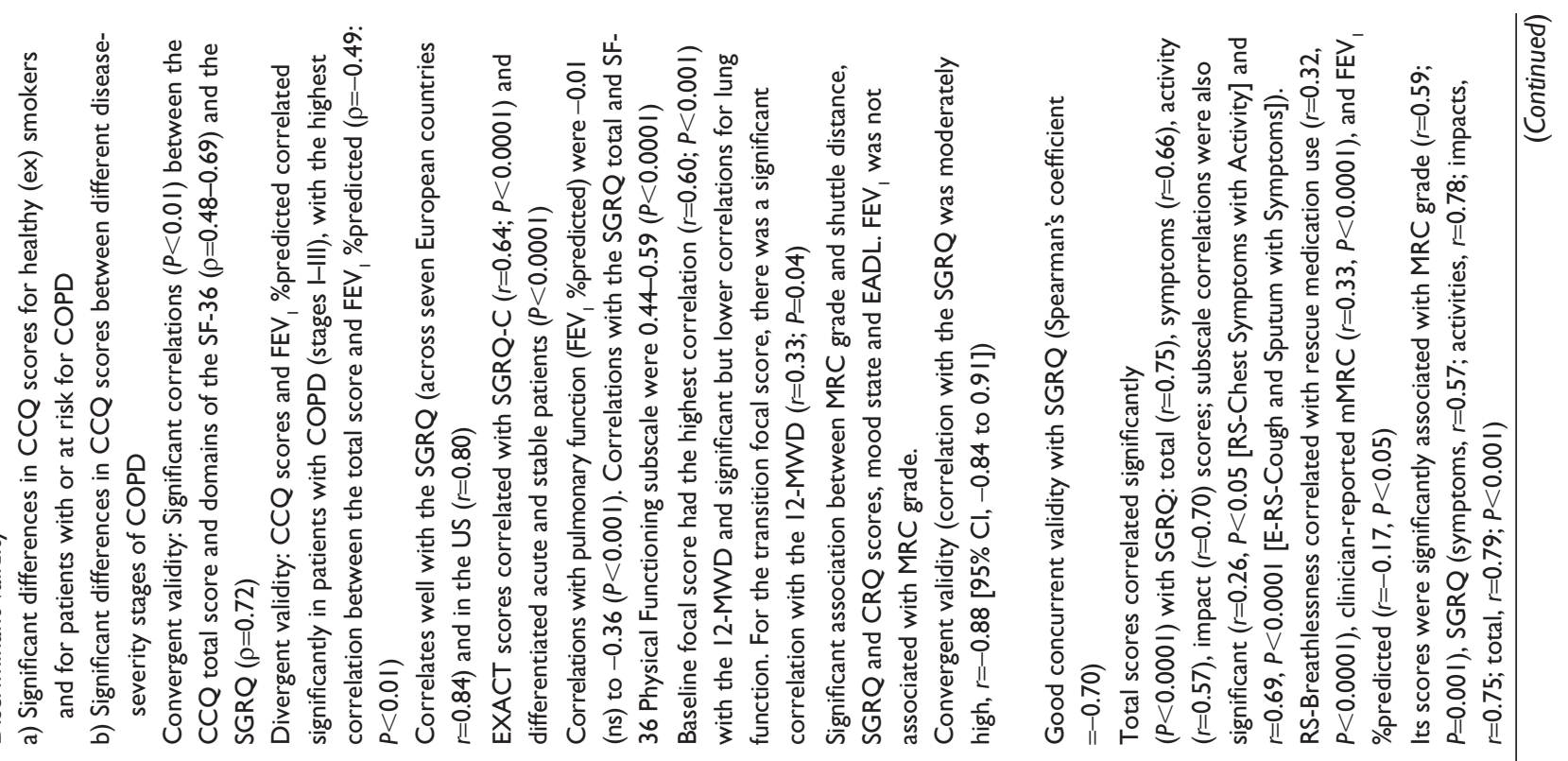

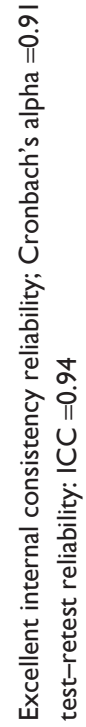
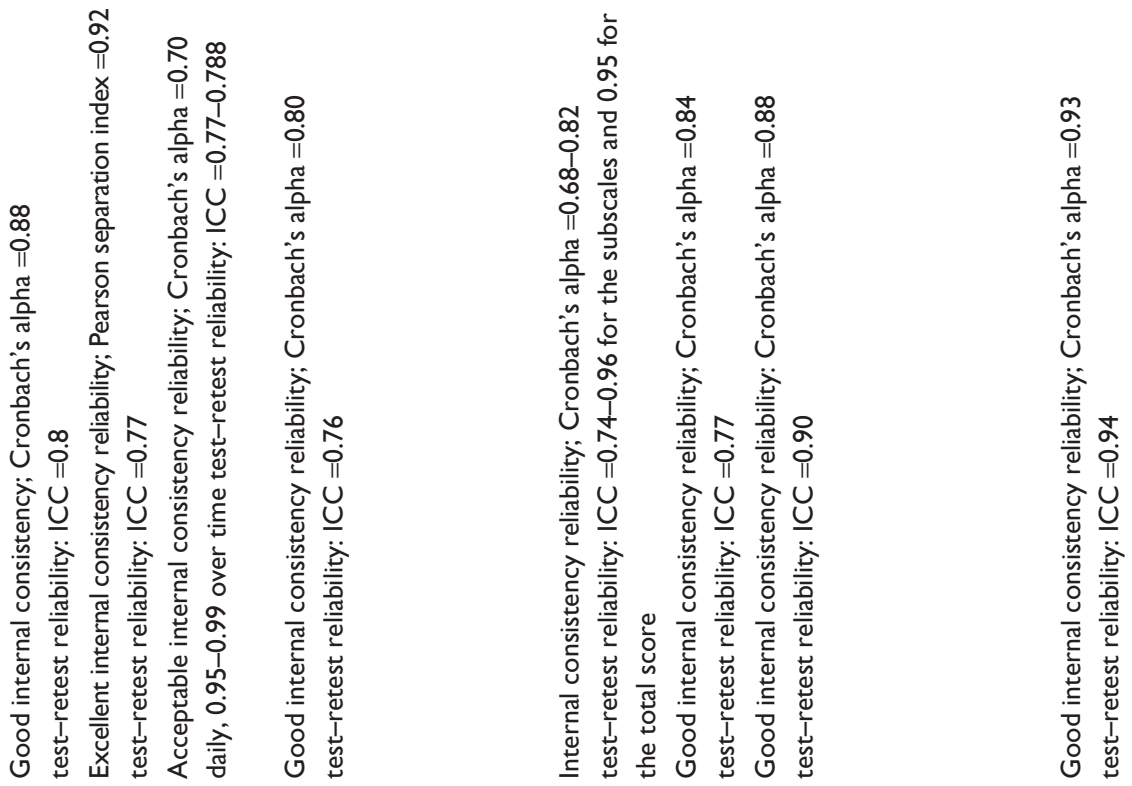

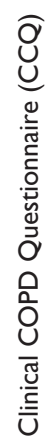
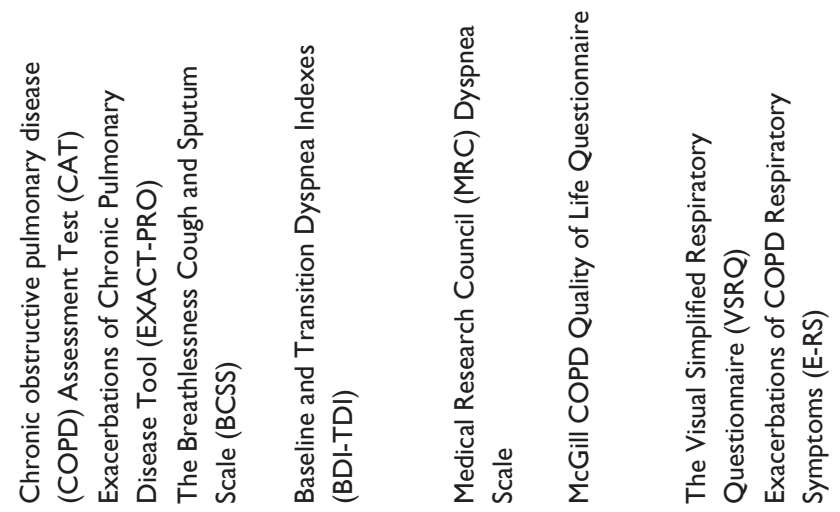

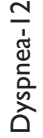




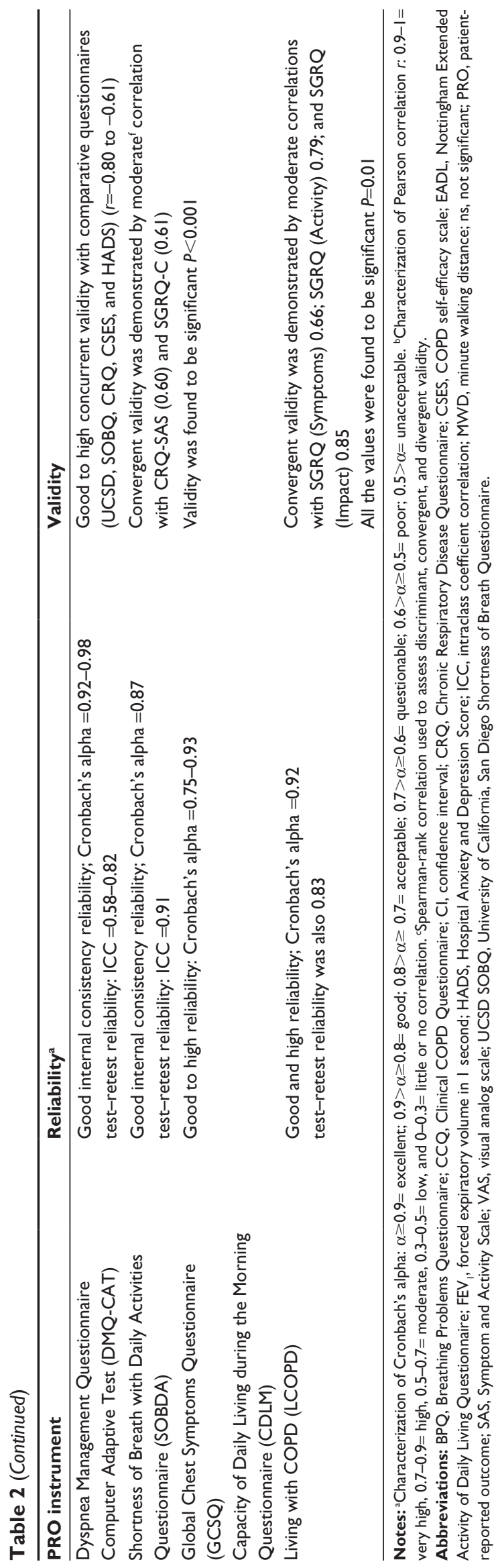

treatment over 6-8 weeks has been demonstrated. ${ }^{26,27}$ The SGRQ is also appropriate to measure the subdomains of Subjective Symptoms and Subjective Impairment. The SGRQ can therefore facilitate the guidance of disease management in COPD. ${ }^{28} \mathrm{~A}$ four-unit change in score is considered as the minimal clinically important difference for this instrument. However, some have argued that the SGRQ has been insufficient at determining the treatment effect of a drug narrowly targeted to a specific aspect of COPD.${ }^{29}$ Furthermore, others had noted that the SGRQ has some limitations, in particular that it is time-consuming to complete and therefore adds to the respondent burden. ${ }^{30}$

\section{SGRQ for COPD (SGRQ-C)}

The SGRQ-C is a 40 -item version of the original 50 -item SGRQ. ${ }^{31}$ It was derived from the original version after a detailed analysis of data from large studies in COPD. The intention was to remove the items with the weakest measurement properties from the original instrument but at the same time ensure that its scores were directly comparable with the original SGRQ. ${ }^{31}$ Rasch modeling (a powerful tool for examining the performance of individual items) ${ }^{32}$ was applied to the SGRQ; this permitted the removal of several weaker items and thereby improved the measurement properties of SGRQ-C. The instrument has the same domains (symptoms, activity, and impact) as the SGRQ and has the capability to calculate a total score. Like the SGRQ, the SGRQ-C has demonstrated good reliability and has showed significant convergent validity with measures of both respiratory function (such as $\mathrm{FEV}_{1}$, 6-minute walking distance) and other PRO measures (such as the Hospital Anxiety and Depression Scale and the Sickness Impact Profile). ${ }^{31}$ Overall, the SGRQ-C is shorter, contains the best of the original items, and produces scores equivalent to the original instrument.

\section{Chronic Respiratory Disease Questionnaire (CRQ)}

The CRQ is a 20-item instrument which aims to measure HRQoL in COPD patients by assessing four domains: a patient's perception of mastery, fatigue, emotional function, and dyspnea experienced during certain activities in the 2 weeks prior to its administration. ${ }^{33}$ The selection of important items was determined through a process that included reviewing current literature, consulting with clinical respiratory specialists, and interviewing patients. The CRQ was developed by using classical test theory and appears to be sensitive to treatment. However, as has been noted, only the standardized version of the CRQ is suitable for group comparisons; the individualised CRQ is less suitable 
for interindividual comparisons because it only documents individual patient limitations. ${ }^{23}$ The CRQ is also one of the most widely used disease-specific questionnaires that provides an overall measure of health status and has been used in many pharmaceutical trials. In addition, the CRQ has been recommended by the European Medicines Agency as a suitable HRQoL instrument that can be used in COPD drug development programs and clinical trials. ${ }^{25}$ The CRQ has demonstrated good psychometric properties of high internal consistency ${ }^{34}$ and good convergent validity. The emotional function domain of the CRQ showed a high correlation with the feelings domain of the generic Dartmouth Co-operative Functional Assessment Charts measure of functional status in patients receiving ambulatory oxygen. ${ }^{35,36}$ The minimal clinically important difference of the CRQ has been consistently reported to be around 0.5 per question with a 0.43 for the dyspnea domain, 0.64 for fatigue, and 0.49 for emotional function. Jaeschke et al in 1989 stated that a CRQ change of 0.81 to 0.96 indicates a moderate effect and that a large effect is indicated by a change of 0.86 to $1.47 .{ }^{37}$

\section{Short Form Chronic Respiratory Disease Questionnaire (SF-CRQ)}

The SF-CRQ contains only eight items of the original 20-item CRQ. Item selection was based on previous research and in consultation with the developer of the original CRQ (Gordon Guyatt). The instrument was pilot tested with consecutive emergency department patients with COPD (number of subjects =301). Like the CRQ, the SF-CRQ has demonstrated good reliability, validity, and responsiveness for the assessment of short-term HRQoL change in patients with COPD exacerbations. ${ }^{38}$

\section{Clinical COPD Questionnaire (CCQ)}

The Clinical COPD questionnaire is a ten-item, selfadministered tool. It was originally called the COPD Control Questionnaire but was later renamed. The CCQ was developed primarily to assess health status in a primary care setting, but it is also useful for measuring the response to intervention in clinical trials and for assessing clinical improvement after smoking cessation. ${ }^{39}$ The CCQ has three domains: symptoms, functional state, and mental state. The scale has two versions, a 7-day recall of COPD status and a 24-hour recall of COPD status. ${ }^{39}$ The CCQ's development suggests strong content validity, and the questionnaire has been used in many pharmaceutical trials. ${ }^{40}$ The CCQ has good psychometric properties, test-retest reliability, responsiveness, and validity. ${ }^{40,41}$ The CCQ has strong discriminative measurement properties; it can be used in all patients with COPD and in patients at risk of COPD. ${ }^{39}$ The CCQ is able to identify patients with poor clinical COPD control and can be used to evaluate the effects of interventions in a standardized way. ${ }^{39}$ Unfortunately, the CCQ has not been widely used to evaluate drugs in pharmaceutical trials. However, the CCQ total score has been shown to have value as a prognostic instrument for mortality in COPD, and the instrument was suggested to indicate which patients are most at risk for clinical interventions. ${ }^{41}$

\section{CAT}

The CAT was developed by Jones et $\mathrm{al}^{8}$ in 2009 to FDA standards, is based on patient interviews, and the content has been reinforced by interviews with community physicians and pulmonologists. It uses Rasch modeling to identify items with the best fit to the unidimensional model. The instrument was developed with the purpose of quantifying the symptom burden of COPD with a concise, simple, and rigorously validated assessment tool. ${ }^{42}$ The CAT has been shown to be reliable and to be sensitive to changes in health status after an exacerbation. The test also has been shown to be responsive to pulmonary rehabilitation in a manner similar to more complex COPD health status measures. ${ }^{43-45}$ The instrument assesses the impact of the disease and, in the current Global Initiative of Chronic Obstructive Lung Disease (GOLD) strategy, it is used to assign appropriate treatments to patients. ${ }^{1}$ Its usefulness as an outcome measure is currently under evaluation in randomized control trials.

\section{Symptom diary measures}

As defined in the recent GOLD strategy document, "An exacerbation is an acute event characterized by the worsening of the patient's respiratory symptoms that is beyond normal day to day variations and leads to a change in medication". ${ }^{1}$ Despite the efforts to understand the effect of treatment on exacerbations in COPD, until recently there was not a standardized PRO measure to evaluate this outcome.

\section{The EXACT-PRO and the E-RS diaries}

The EXACT-PRO is a 14-item PRO measure that evaluates the frequency, severity, and duration of acute exacerbations of COPD. ${ }^{46,47}$ The EXACT-PRO was developed in collaboration with experts in instrument development and validation, specialists in clinical practice and research, and experts from the FDA. ${ }^{47,48}$ The EXACT-PRO daily diary is designed to be completed by the patients before bedtime. Initial testing of the EXACT-PRO in an observational study 
of patients with COPD indicated that the scale has scores that are internally consistent and reproducible in stable patients and that the scale correlates with clinical variables (eg, SGRQ-C). ${ }^{46,47}$ Furthermore, this instrument has the ability to differentiate acute and stable patients, to measure change over time in exacerbations, and to differentiate physicianand patient-rated exacerbation severity. ${ }^{46,47}$ The minimum changes that represent onset of and recovery from an exacerbation are under investigation.

The E-RS has been developed from the EXACT-PRO tool by using eleven of the 14 EXACT items to measure the cardinal symptoms of COPD (cough, chest symptoms, and breathlessness). The E-RS is described to have been developed consistently with good PRO research practices and FDA PRO requirements. The E-RS is a reliable and valid measure for evaluating the severity of respiratory symptoms in patients with COPD. ${ }^{49-51}$

\section{The Breathlessness Cough and Sputum Scale (BCSS)} The BCSS is a brief, three-item, easy-to-use instrument that can be used for tracking the severity of respiratory symptoms and for evaluating efficacy of treatment in clinical trials of patients with COPD. ${ }^{52,53}$ Designed as part of a daily diary, subjects are asked to assess and record the severity of three symptoms of COPD: breathlessness, cough, and sputum. ${ }^{52,53}$ The BCSS is a reliable and valid measure of symptom severity. ${ }^{52,53}$ A mean change in BCSS total score of $>1.0$ represents substantial symptomatic improvement. Changes of approximately 0.6 can be interpreted as moderate, and changes of 0.3 can be considered small. ${ }^{51}$

\section{Breathlessness/dyspnea measures}

Breathlessness is a commonly reported symptom in patients with COPD. ${ }^{1}$ Persistent breathlessness can impair a patient's HRQoL; therefore, alleviating breathlessness among COPD patients is also an important goal. ${ }^{1}$

\section{Baseline Dyspnea Index and Transition Dyspnea Index}

The Baseline Dyspnea Index (BDI) and Transition Dyspnea Index (TDI) were developed in 1984 by using data from patients with COPD, asthma, and interstitial fibrosis. ${ }^{54}$ The BDI is a discriminative instrument used to quantify the severity of dyspnea in clinically stable patients. The TDI is an instrument used to quantify the changes in dyspnea from the baseline state with the purpose of providing a multidimensional assessment of dyspnea. The BDI and the TDI are both three-item instruments that assess COPD on the bases of functional impairment and the magnitude of task and effort of daily activities in the 2 weeks prior to administration. ${ }^{55}$ When used together, the indices are referred to as one measure, the BDI-TDI. The BDI-TDI has been widely used together as a clinician-reported measure rather than a PRO instrument.

The BDI-TDI is a validated tool that is sensitive to intervention and that was originally designed as a physician interview with the patient. ${ }^{55}$ In an observational study, the BDI and the TDI were shown to be responsive to changes in dyspnea associated with a COPD exacerbation. ${ }^{51}$ A self-administered computerized version of the TDI became available in 2004 and avoids any interviewer interpretation. ${ }^{56}$ Results using the self-administered computerized version of the TDI can be collected and analyzed electronically on a continuous scale. In a comparison with the CRQ, both the self administered and computerised measures were reported as having good construct and concurrent validity. No clear superiority of either measure has been shown. However, as the patient has to recall baseline state (BDI) in order to answer questions regarding the TDI, there is a high probability of recall bias in the assessment. ${ }^{57}$

\section{The Medical Research Council (MRC) Dyspnea Scale} The MRC breathlessness scale was developed in $1960^{9}$ and comprises five statements that describe the range of respiratory disability due to breathlessness from none (Grade 1) to almost complete incapacity (Grade 5). The MRC breathlessness scale does not quantify breathlessness itself; rather, it quantifies the disability associated with breathlessness by identifying whether breathlessness occurs when it should not (Grades 1 and 2) or by quantifying the associated exercise limitation (Grades 3-5). The MRC dyspnea scale is widely used to describe patient cohorts and stratify them for interventions, such as pulmonary rehabilitation. ${ }^{9}$ It is advocated as a complementary measure to $\mathrm{FEV}_{1}$ in COPD patients to describe disability. ${ }^{58,59}$ Originally rated by the clinician, it can also be self-administered. All the questions relate to everyday activities and are generally easily understood by patients. The score correlates well with other breathlessness scales, lung function measurements, and direct measures of disability such as walking distance. ${ }^{58,59}$ Its main disadvantage over other more complex scales is its poorer responsiveness to interventions.

\section{The $\mathrm{m}-\mathrm{MRC}$}

The $\mathrm{m}-\mathrm{MRC}$ has a revised response scale from $0-4$ (instead of $1-5$ in the MRC scale) and is mostly self-administered. ${ }^{60}$ A comparison study found that the m-MRC and the BDI were moderately correlated and thus demonstrated concurrent 
validity. ${ }^{61}$ In the same study, the BDI showed association with physiological measures, whereas the m-MRC was not significantly related with physiological measures. ${ }^{62}$ It was not clear from the publication whether the m-MRC was completed independently by the patient or administered by the physician, a variable which may explain the difference in the outcome because the clinician may be unblinded to the spirometry findings. The current GOLD classification uses the m-MRC and CAT along with exacerbation history and airflow limitation to classify patients into four COPD categories grades (A-D). ${ }^{1}$ The modification from the $1-5$ scale to the $0-4$ scale has not changed the measure's fundamental structure, and hence the tool has inherited the problems from the original MRC scale; these include low responsiveness and therefore infrequent use as an outcome measure in pharmaceutical trials.

\section{Emerging PRO measures in COPD}

In addition to the commonly used PRO measures, a number of new measures have been developed over the past few years: the McGill COPD Quality of Life Questionnaire, ${ }^{63,64}$ the Visual Simplified Respiratory Questionnaire, ${ }^{65}$ the Dyspnea-12, ${ }^{66,67}$ the Dyspnea Management Questionnaire Computer Adaptive Test, ${ }^{68,69}$ the Shortness of Breath with Daily Activities questionnaire,$^{70}$ the Global Chest Symptoms Questionnaire, ${ }^{71}$ the Capacity of Daily Living during the Morning questionnaire, ${ }^{71}$ and Living with COPD Questionnaire. ${ }^{72}$ However, their use and value are still to be determined; as more knowledge about their reliability and validity, and their responsiveness to treatment need to be further evaluated. These instruments are described in detail along with their psychometric properties in Tables 1 and 2 .

\section{Discussion}

The COPD patient population is heterogeneous in terms of clinical presentation, disease severity, and rate of disease progression; therefore, there is currently no agreement on what constitutes a desirable response to pharmacological interventions. The absence of a clear biomarker of disease progression also complicates how clinicians evaluate treatment efficacy. PRO measurements of dyspnea or functional status provide insights into the effects of treatment on everyday life by reflecting whether or not patients perceive improvement in their symptoms or their abilities to perform daily activities, regardless of whether $\mathrm{FEV}_{1}$ has improved or not. This feature may be particularly useful when a treatment has multiple beneficial effects, which individually may be too small to register as a change on an assessment of an individual parameter but collectively may produce improvement.

Therefore, it appears useful to include PRO instruments in the evaluation of pharmaceutical interventions as well as other health care interventions (such as pulmonary rehabilitation). Our article summarized the benefits and characteristics of the main instruments.

We have neither compared nor recommended specific instruments for the reader as it is difficult to recommend a specific instrument without a solid understanding of the research question of the study and the situation in which the instruments will be used. In a scenario in which someone may have limited time to administer an instrument, a quick instrument such as the CCQ, SF-CRQ, or CAT tool has more merit than a longer instrument such as the SGRQ or the CRQ. If a researcher is interested in the assessment of control or mastery that the patient feels over their COPD, then the CRQ may be advisable, whereas if the intent is to explore the variability of symptomatology during an exacerbation, the EXACT or the E-RS may offer more value.

To ensure the comprehensiveness of this review, we would like to include a few references of studies that directly compare the psychometric criteria of these instruments, ${ }^{27,73,74}$ but again would like to stress that we were not directly involved in those research studies and the conclusions drawn.

\section{Conclusion}

In order to completely understand the effects of therapies that are relevant to patients with COPD, PRO instruments need to be valid, reliable, responsive to clinically meaningful treatment effects, adaptable across various populations, and ideally understandable to patients and physicians by using easy to interpret scoring systems that are relevant to health care providers and acceptable to regulatory authorities. ${ }^{15}$ Some of the instruments reviewed in this paper address multidimensional aspects of HRQoL. Most of them are included in the assessments of symptoms, physical functioning, and psychosocial well-being. A further concern with old PRO measures was their low responsiveness to pharmaceutical interventions, a factor that could reflect ineffective treatments but could also reflect the insensitivity of older tools to detect change. Recently, COPD field has progressed much more in assessing patients' daily living activities but published information needs to be established. ${ }^{75}$ It would be very useful for the clinical community to update this review in 3-5 years, when more information around the value of these instruments is available. One of the most promising instruments 
is probably the physical activity assessment in the European Innovative Medicines Initiative PRO-active project. ${ }^{76}$

Of these instruments, the CCQ, EXACT/E-RS, and the CAT appear to be the most promising because compared to the others, these are shorter and pose lower respondent burdens and, therefore, may be preferable to patients. The CCQ, EXACT/E-RS, and CAT seem to have demonstrated some validity and responsiveness to treatment in various studies. However, data on the development and validation of these new and promising COPD-specific instruments are still emerging. Future challenges for regulatory authorities such as the FDA and the European Medicines Agency, as well as health technology assessment agencies and clinicians, will be to keep up to date with the development of comprehensive COPD PRO instruments that may be used in drug development, therapeutic interventions, research, and clinical practice.

\section{Acknowledgment}

The authors of the manuscript would like to thank Shalaka Marfatia from pharmEDGE for providing writing and editorial support on the second and subsequent versions of the draft manuscript.

\section{Disclosure}

M Cazzola reports receiving personal fees from Pfizer, grants and personal fees from Almirall, grants and personal fees from Novartis, personal fees from GlaxoSmithKline, personal fees from Chiesi Farmaceutici, personal fees from Verona Pharma, and personal fees from Boehringer Ingelheim during the conduct of the study. NA Hanania reports receiving grants and personal fees from GlaxoSmithKline, grants from Boehringer Ingelheim, grants and personal fees from Sunovion, grants from Mylan, and grants and personal fees from Pfizer outside the submitted work. W MacNee reports receiving personal fees from Pfizer, personal fees from Almirall, personal fees from GlaxoSmithKline, personal fees from Novartis, personal fees from Janssen, grants from the British Heart Foundation, grants from the Chief Scientist Office, grants from the MRC, personal fees and other awards from AstraZeneca, and other awards from Boehringer Ingelheim outside the submitted work. Other than her employment, $\mathrm{K}$ Rüdell has nothing to disclose. C Hackford has nothing to disclose. N Tamimi has nothing to disclose.

The initial literature search and review were conducted by Pfizer employees as part of their current work with no specific funding information, and no funding was provided to the academic contributors for their review of the findings and writing of the document. After the submission of the original drafts, Pfizer provided $\$ 15,000$ to provide editorial writing support to streamline the document and fulfill journal requirements for writing style, length, formatting, etc. The authors report no other conflicts of interest in this work.

\section{References}

1. Pocket Guide to COPD Diagnosis, Management, and Prevention [webpage on Internet]. Global Initiative for Chronic Obstructive Lung Disease; 2014. Available from: http://www.goldcopd.org/guidelinespocket-guide-to-copd-diagnosis.html. Accessed December 17, 2014.

2. Jones PW, Agusti AG. Outcomes and markers in the assessment of chronic obstructive pulmonary disease. Eur Respir J. 2006;27(4):822-832.

3. Centers for Disease Control and Prevention. Morbidity and Mortality Weekly Reports. Atlanta: Centers for Disease Control and Prevention; 2012. Available from: http://www.cdc.gov/mmwr/pdf/wk/mm6146. pdf. Accessed December 17, 2014.

4. Jones PW. Health status measurement in chronic obstructive pulmonary disease. Thorax. 2001;56(11):880-887.

5. Oga T, Nishimura K, Tsukino M, Sato S, Hajiro T, Mishima M. Longitudinal deteriorations in patient reported outcomes in patients with COPD. Respir Med. 2007;101(1):146-153.

6. Westwood M, Bourbeau J, Jones PW, Cerulli A, Capkun-Niggli G, Worthy G. Relationship between $\mathrm{FEV}_{1}$ change and patient-reported outcomes in randomised trials of inhaled bronchodilators for stable COPD: a systematic review. Respir Res. 2011;12:40.

7. Agusti A, Edwards LD, Celli B, et al. Characteristics, stability and outcomes of the 2011 GOLD COPD groups in the ECLIPSE cohort. Eur Respir J. 2013;42(3):636-646.

8. Jones PW, Harding G, Berry P, Wiklund I, Chen WH, Kline Leidy N. Development and first validation of the COPD Assessment Test. Eur Respir J. 2009;34(3):648-654.

9. Fletcher CM. (1960) Standardised questionnaire on respiratory symptoms: a statement prepared and approved by the MRC Committee on the Aetiology of Chronic Bronchitis (MRC breathlessness score). BMJ 2:1665. (Chairman).

10. Cazzola M, MacNee W, Martinez FJ, et al; European Respiratory Society Task Force on outcomes of COPD. Outcomes for COPD pharmacological trials: from lung function to biomarkers. Eur Respir J. 2008;31(2):416-469.

11. Jones PW. Issues concerning health-related quality of life in COPD. Chest. 1995;107(5 Suppl):187S-193S.

12. Calvert M, Blazeby J, Altman DG, Revicki DA, Moher D, Brundage MD; CONSORT PRO Group. Reporting of patient-reported outcomes in randomized trials: the CONSORT PRO extension. JAMA. 2013; 309(8):814-822.

13. Doward LC, McKenna SP. Defining patient-reported outcomes. Value in Health. 2004; 7(Suppl 1):S4-S8.

14. US Food and Drug Administration. Chronic obstructive pulmonary disease: Developing drugs for treatment (Draft guidance for industry). In: CDER, ed2007. Silver Spring: US Food and Drug Administration; 2007. Available from: http://www.fda.gov/downloads/Drugs/GuidanceComplianceRegulatoryInformation/Guidances/ucm071575.pdf. Accessed December 17, 2014.

15. US Food and Drug Administration. Guidance for Industry: PatientReported Outcome Measures: Use in Medical Product Development to Support Labeling Claims. In: Research CfDEa, ed2009. Silver Spring: US Food and Drug Administration; 2009. Available from: http://www. fda.gov/downloads/Drugs/GuidanceComplianceRegulatoryInformation/Guidances/UCM193282.pdf. Accessed December 17, 2014. 
16. US Food and Drug Administration. Guidance for Industry and FDA staff: Qualification Process for Drug Development Tools. In: CDER, ed2014. Silver Spring: US Food and Drug Administration; 2009. Available from: http://www.fda.gov/downloads/Drugs/GuidanceComplianceRegulatoryInformation/Guidances/UCM230597.pdf. Accessed December 17, 2014.

17. Fitzpatrick R, Bowling A, Gibbons E, et al. A Structured Review of Patient-Reported Measures in Relation to Selected Chronic Conditions, Perceptions of Quality of Care and Carer Impact. Report to the Department of Health. Oxford: National Centre for Health Outcomes Development, University of Oxford; 2006. Available from: http://phi.uhce. ox.ac.uk/pdf/ChronicConditions/DH_REVIEWS_NOVEMBER_2007. pdf. Accessed December 17, 2014.

18. Esteban C, Quintana JM, Aburto M, et al. Impact of changes in physical activity on health-related quality of life among patients with COPD. Eur Respir J. 2010;36(2):292-300.

19. Weldam SW, Schuurmans MJ, Liu R, Lammers JW. Evaluation of Quality of Life instruments for use in COPD care and research: a systematic review. Int J Nurs Stud. 2013;50(5):688-707.

20. Barlow J, Smailagic N, Bennett C, Huband N, Jones H, Coren E. Individual and group based parenting programmes for improving psychosocial outcomes for teenage parents and their children. Cochrane Database Syst Rev. 2011;(3):CD002964.

21. Jones PW, Quirk FH, Baveystock CM. The St George's Respiratory Questionnaire. Respir Med. 1991;85(Suppl 2):25-31.

22. Jones PW, Quirk FH, Baveystock CM, Littlejohns P. A self-complete measure of health status for chronic airflow limitation. The St. George's Respiratory Questionnaire. Am Rev Respir Dis. 1992;145(6):1321-1327.

23. Glaab T, Vogelmeier C, Buhl R. Outcome measures in chronic obstructive pulmonary disease (COPD): strengths and limitations. Respir Res. 2010;11:79.

24. McGlone S, Venn A, Walters EH, Wood-Baker R. Physical activity, spirometry and quality-of-life in chronic obstructive pulmonary disease. COPD. 2006;3(2):83-88.

25. European Medicines Agency. Guidance on the Clinical Investigation for Medicinal Products for Chronic Obstructive Pulmonary Disorder. London: European Medicines Agency; 2012. Available from: http:/ www.ema.europa.eu/docs/en_GB/document_library/Scientific_ guideline/2012/08/WC500130880.pdf. Accessed December 17, 2015.

26. Brown CD, Benditt JO, Sciurba FC, et al. Exercise testing in severe emphysema: association with quality of life and lung function. COPD. 2008;5(2):117-124.

27. Rutten-van Mölken M, Roos B, Van Noord JA. An empirical comparison of the St George's Respiratory Questionnaire (SGRQ) and the Chronic Respiratory Disease Questionnaire (CRQ) in a clinical trial setting. Thorax. 1999;54(11):995-1003.

28. Franciosi LG, Page CP, Celli BR, et al. Markers of exacerbation severity in chronic obstructive pulmonary disease. Respir Res. 2006;7:74.

29. Daudey L, Peters JB, Molema J, et al. Health status in COPD cannot be measured by the St George's Respiratory Questionnaire alone: an evaluation of the underlying concepts of this questionnaire. Respir Res. 2010;11:98.

30. Campbell M, Eliraz A, Johansson G, et al. Formoterol for maintenance and as-needed treatment of chronic obstructive pulmonary disease. Respir Med. 2005;99(12):1511-1520.

31. Meguro M, Barley EA, Spencer S, Jones PW. Development and Validation of an Improved, COPD-Specific Version of the St. George Respiratory Questionnaire. Chest. 2007;132(2):456-463.

32. Fischer GH, Molenaar IW. Rasch Models. Foundations, Recent Developments and Applications. New York: Springer; 1995

33. Guyatt GH, Berman LB, Townsend M, Pugsley SO, Chambers LW. A measure of quality of life for clinical trials in chronic lung disease. Thorax. 1987;42(10):773-778.

34. Kapella MC, Larson JL, Patel MK, Covey MK, Berry JK. Subjective fatigue, influencing variables, and consequences in chronic obstructive pulmonary disease. Nurs Res. 2006;55(1):10-17.
35. Berry MJ, Adair NE, Rejeski WJ. Use of peak oxygen consumption in predicting physical function and quality of life in COPD patients. Chest. 2006;129(6):1516-1522.

36. Eaton T, Young P, Fergusson W, Garrett JE, Kolbe J. The Dartmouth COOP Charts: a simple, reliable, valid and responsive quality of life tool for chronic obstructive pulmonary disease. Qual Life Res. 2005;14(3):575-585.

37. Jaeschke R, Singer J, Guyatt GH. Measurement of health status. Ascertaining the minimal clinically important difference. Control Clin Trials. 1989;10(4):407-415.

38. Tsai CL, Hodder RV, Page JH, Cydulka RK, Rowe BH, Camargo CA Jr. The short-form chronic respiratory disease questionnaire was a valid, reliable, and responsive quality-of-life instrument in acute exacerbations of chronic obstructive pulmonary disease. J Clin Epidemiol. 2008;61(5):489-497.

39. van der Molen T, Willemse BW, Schokker S, ten Hacken NH, Postma DS, Juniper EF. Development, validity and responsiveness of the Clinical COPD Questionnaire. Health Qual Life Outcomes. 2003;1:13.

40. Ställberg B, Nokela M, Ehrs PO, Hjemdal P, Jonsson EW. Validation of the clinical COPD Questionnaire (CCQ) in primary care. Health Qual Life Outcomes. 2009;7:26.

41. Sundh J, Janson C, Lisspers K, Montgomery S, Ställberg B. Clinical COPD Questionnaire score (CCQ) and mortality. Int J Chron Obstruct Pulmon Dis. 2012;7:833-842.

42. Jones PW, Brusselle G, Dal Negro RW, et al. Properties of the COPD assessment test in a cross-sectional European study. Eur Respir J. 2011; 38(1):29-35

43. Jones P, Harding G, Wiklund I, Berry P, Leidy N. Improving the process and outcome of care in COPD: development of a standardised assessment tool. Prim Care Respir J. 2009;18(3):208-215.

44. Dodd JW, Hogg L, Nolan J, et al. The COPD assessment test (CAT): response to pulmonary rehabilitation. A multicentre, prospective study. Thorax. 2011;66(5):425-429.

45. Dodd JW, Marns PL, Clark AL, et al. The COPD Assessment Test (CAT): short- and medium-term response to pulmonary rehabilitation. COPD. 2012;9(4):390-394.

46. Leidy NK, Wilcox TK, Jones PW, et al. Development of the EXAcerbations of Chronic Obstructive Pulmonary Disease Tool (EXACT): a patientreported outcome (PRO) measure. Value Health. 2010;13(8):965-975.

47. Leidy NK, Wilcox TK, Jones PW, Roberts L, Powers JH, Sethi S; EXACTPRO Study Group. Standardizing measurement of chronic obstructive pulmonary disease exacerbations. Reliability and validity of a patientreported diary. Am J Respir Crit Care Med. 2011;183(3):323-329.

48. Jones PW, Chen WH, Wilcox TK, Sethi S, Leidy NK; EXACT-PRO Study Group. Characterizing and quantifying the symptomatic features of COPD exacerbations. Chest. 2011;139(6):1388-1394.

49. Leidy NK, Murray LT, Monz BU, et al. Measuring respiratory symptoms of COPD: performance of the EXACT-Respiratory Symptoms Tool (E-RS) in three clinical trials. Respir Res. 2014;15(1):124.

50. Leidy NK, Sexton CC, Jones PW, et al. Measuring respiratory symptoms in clinical trials of COPD: reliability and validity of a daily diary. Thorax. 2014;69(5):443-449.

51. Murray LT, Houle C, Stolar M, et al. Quantifying the Severity of Respiratory Symptoms of COPD: Performance Properties of the E-RS in 3 Randomized Control Trials. In: Respiratory Clinical Care Medicine American Thoracic Society International Conference Issue; May 18-23, 2012; San Francisco, CA, USA. Available from: http://www.atsjournals. org/doi/abs/10.1164/ajrccm-conference.2012.185.1_MeetingAbstracts. A1515. Accessed December 17, 2015.

52. Leidy NK, Rennard SI, Schmier J, Jones MK, Goldman M. The breathlessness, cough, and sputum scale: the development of empirically based guidelines for interpretation. Chest. 2003;124(6):2182-2191.

53. Leidy NK, Schmier JK, Jones MK, Lloyd J, Rocchiccioli K. Evaluating symptoms in chronic obstructive pulmonary disease: validation of the Breathlessness, Cough and Sputum Scale. Respir Med. 2003;97(Suppl A): S59-S70. 
54. Mahler DA, Weinberg DH, Wells CK, Feinstein AR. The measurement of dyspnea. Contents, interobserver agreement, and physiologic correlates of two new clinical indexes. Chest. 1984;85(6):751-758.

55. Mahler DA, Wells CK. Evaluation of clinical methods for rating dyspnea. Chest. 1988;93(3):580-586.

56. Mahler DA, Ward J, Fierro-Carrion G, et al. Development of selfadministered versions of modified baseline and transition dyspnea indexes in COPD. COPD. 2004;1(2):165-172.

57. Hareendran A, Leidy NK, Monz BU, Winnette R, Becker K, Mahler DA. Proposing a standardized method for evaluating patient report of the intensity of dyspnea during exercise testing in COPD. Int J Chron Obstruct Pulmon Dis. 2012;7:345-355.

58. Wedzicha JA, Bestall JC, Garrod R, Garnham R, Paul EA, Jones PW. Randomized controlled trial of pulmonary rehabilitation in severe chronic obstructive pulmonary disease patients, stratified with the MRC dyspnoea scale. Eur Respir J. 1998;12(2):363-369.

59. Bestall JC, Paul EA, Garrod R, Garnham R, Jones PW, Wedzicha JA. Usefulness of the Medical Research Council (MRC) dyspnoea scale as a measure of disability in patients with chronic obstructive pulmonary disease. Thorax. 1999;54(7):581-586.

60. Nishimura K, Izumi T, Tsukino M, Oga T. Dyspnea is a better predictor of 5-year survival than airway obstruction in patients with COPD. Chest. 2002;121(5):1434-1440.

61. Chhabra SK, Gupta AK, Khuma MZ. Evaluation of three scales of dyspnea in chronic obstructive pulmonary disease. Ann Thorac Med. 2009;4(3):128-132.

62. Aaron SD, Vandemheen KL, Clinch JJ, et al. Measurement of shortterm changes in dyspnea and disease-specific quality of life following an acute COPD exacerbation. Chest. 2002;121(3):688-696.

63. Pakhale S, Wood-Dauphinee S, Spahija J, et al. Combining both generic and disease-specific properties: development of the McGill COPD quality of life questionnaire. COPD. 2011;8(4):255-263.

64. Pakhale S, Wood-Dauphinee S, Spahija A, et al. Validation of a new questionnaire with generic and disease-specific qualities: the McGill COPD Quality of Life Questionnaire. Canadian Respir J. 2012;19(6): 367-372.

65. Perez T, Arnould B, Grosbois JM, et al. Validity, reliability, and responsiveness of a new short Visual Simplified Respiratory Questionnaire (VSRQ) for health-related quality of life assessment in chronic obstructive pulmonary disease. Int J Chron Obstruct Pulmon Dis. 2009;4:9-18.

66. Yorke J, Moosavi SH, Shuldham C, Jones PW. Quantification of dyspnoea using descriptors: development and initial testing of the Dyspnoea-12. Thorax. 2010;65(1):21-26.
67. Yorke J, Swigris J, Russell AM, et al. Dyspnea-12 is a valid and reliable measure of breathlessness in patients with interstitial lung disease. Chest. 2011;139(1):159-164.

68. Norweg A, Ni P, Garshick E, O’Connor G, Wilke K, Jette AM. A multidimensional computer adaptive test approach to dyspnea assessment. Arch Phys Med Rehabil. 2011;92(10):1561-1569.

69. Norweg A, Jette AM, Ni P, Whiteson J, Kim M. Outcome measurement for COPD: reliability and validity of the Dyspnea Management Questionnaire. Respir Med. 2011;105(3):442-453.

70. Wilcox TK, Chen WH, Howard KA, et al. Item selection, reliability and validity of the Shortness of Breath with Daily Activities (SOBDA) questionnaire: a new outcome measure for evaluating dyspnea in chronic obstructive pulmonary disease. Health Qual Life Outcomes. 2013;11:196.

71. Partridge MR, Miravitlles M, Ståhl E, Karlsson N, Svensson K, Welte T. Development and validation of the Capacity of Daily Living during the Morning questionnaire and the Global Chest Symptoms Questionnaire in COPD. Eur Respir J. 2010;36(1):96-104.

72. Garrod R, Bestall JC, Paul EA, Wedzicha JA, Jones PW. Development and validation of a standardized measure of activity of daily living in patients with severe COPD: the London Chest Activity of Daily Living scale (LCADL). Respir Med. 2000;94(6):589-596.

73. Ringbaek T, Martinez G, Lange P. A comparison of the assessment of quality of life with CAT, CCQ, and SGRQ in COPD patients participating in pulmonary rehabilitation. COPD. 2012;9(1):12-15.

74. Tsiligianni IG, van der Molen T, Moraitaki D, et al. Assessing health status in COPD. A head-to-head comparison between the COPD assessment test (CAT) and the clinical COPD questionnaire (CCQ). BMC Pulm Med. 2012;12:20.

75. Frei A, Williams K, Vetsch A, et al; PROactive consortium. A comprehensive systematic review of the development process of 104 patientreported outcomes (PROs) for physical activity in chronically ill and elderly people. Health and quality of life outcomes. 2011;9:116.

76. Dobbels F, de Jong C, Drost E, et al; PROactive consortium. The PROactive innovative conceptual framework on physical activity. Eur Respir J. 2014;44(5):1223-1233.

77. McKenna SP, Meads DM, Doward LC, et al. Development and validation of the living with chronic obstructive pulmonary disease questionnaire. Qual Life Res. 2011;20:1043-1052.
International Journal of COPD

\section{Publish your work in this journal}

The International Journal of COPD is an international, peer-reviewed journal of therapeutics and pharmacology focusing on concise rapid reporting of clinical studies and reviews in COPD. Special focus is given to the pathophysiological processes underlying the disease, intervention programs, patient focused education, and self management protocols.

\section{Dovepress}

This journal is indexed on PubMed Central, MedLine and CAS. The manuscript management system is completely online and includes a very quick and fair peer-review system, which is all easy to use. Visit http://www.dovepress.com/testimonials.php to read real quotes from published authors. 